STATE OF FLORIDA

DEPARTMENT OF ENVIRONMENTAL PROTECTION

Jonathan P. Steverson, Secretary

REGULATORY PROGRAMS

Paula L. Cobb, Deputy Secretary

FLORIDA GEOLOGICAL SURVEY

Jonathan D. Arthur, State Geologist and Director

OPEN FILE REPORT 99

\title{
A GEOPHYSICAL DELINEATION OF THE THICKNESS OF UNCONSOLIDATED SEDIMENTS ON THE INNER CONTINENTAL SHELF OFFSHORE OF ST. LUCIE COUNTY, FLORIDA
}

By

Daniel C. Phelps and Alan E. Baker

Florida Geological Survey

Tallahassee, Florida

April 28, 2015

ISSN 1058-1391 


\section{FLORIDA GEOLOGICAL SURVEY}

\section{A geophysical delineation of the thickness of unconsolidated sediments on the inner continental shelf offshore of St. Lucie County, Florida}

Daniel C. Phelps, (P.G. \# 1203) and Alan E. Baker (P.G. \# 2324)

\section{INTRODUCTION}

The Florida Geological Survey (FGS) analyzed all available sub-bottom profiler data for offshore St. Lucie County and for adjacent areas of Indian River County to the north and Martin County to the south. These analyses were performed to delineate the thickness of unconsolidated sediments on the inner continental shelf, some of which could be suitable for beach replenishment. The unconsolidated sediment thickness was calculated by subtracting the elevation of the sea floor from the elevation of the top of the first consolidated sediments. The top of consolidated sediments is referred to as the "Blue Reflector" in Meisburger and Duane (1971). Two sets of sub-bottom profiler data were examined for this study, "boomer" data that were collected in 1998, 1999 (Forde et al., 2013) and (2000 Subino et al., 2009) by the Florida Geological Survey (FGS) in coordination with the US Geological Survey (USGS) and "chirp" data which were collected in 2006 (Finkl et al., 2006), 2007 (URS Corp., 2007) and 2011. The tracks of these data sets are shown on Figure 1. These data sets can be accessed from the Reconnaissance Offshore Sand Search (http://ross.urs-tally.com/) website. Only chirp data were used to delineate unconsolidated sediment thickness.

The chirp data were collected using EdgeTech 512i sub-bottom profiler systems. The survey conducted in 2006 by Coastal Planning and Engineering Corporation (CPE) was in state waters. They surveyed three relatively small areas with a fairly tight grid density of east-west trending lines crossed by north-south trending tie lines. The east-west lines for two of the three areas lie at approximately a 200 foot (61 meter) north-south line spacing. The grid for the third area lies at approximately a 400 foot (122 meter) line spacing. The goal of the survey was to investigate specific features lying within state waters offshore of St. Lucie County, Florida. The survey in 2007 was conducted by CPE in coordination with URS Corporation. It was conducted within state waters using a widely spaced zig-zag grid of alternating eastwest and northwest-southeast transects within the study area. Collected as part of a multi-county project, that survey extended from the Georgia-Florida border in Nassau County through Martin County. The portion of that survey which was conducted offshore of St. Lucie County as well as portions of the survey which crossed the border of St. Lucie County to the north and south were used. Some of the lines from that survey cross lines collected in the 2006 survey. The third of these chirp surveys was conducted in 2011, primarily in federal waters, by Coastal Technology Corporation. It overlaps, in part, with the southernmost portions of the 2006 CPE survey. It surveyed two relatively small areas with a fairly tight grid density of east-west trending lines at approximately a 250 foot (76.2 meter) line spacing crossed by northsouth trending tie lines. Its goal was to investigate specific features lying primarily in federal waters offshore of St. Lucie County.

The boomer data were collected by the FGS using equipment and personnel supplied by the USGS. It was part of a multi-year study, funded by the Department of the Interior's Minerals Management Service (now the Bureau of Ocean Energy Management), that ultimately included surveying in federal waters out to approximately 18 nautical miles (33.3 kilometers) off the northeast and central east coast of Florida. It consists of a widely spaced grid of east-west lines, at approximately 0.5 nautical mile ( 0.93 kilometer) spacing, crossed by a series of northwest-southeast trending lines oriented along a single transect. 


\section{DATA ISSUES}

While the four sub-bottom profiler data sets available for this study are somewhat overlapping, not all east-west oriented lines are crossed by north-south tie lines or by lines from previous or subsequent surveys. This is particularly true of the 2007 data, as that survey was not conducted with tie lines. The chirp data from all three cruises are of a uniformly higher resolution than the boomer data, albeit with significantly lower penetration. As the horizon to be mapped lies within the first 65.6 feet (20 meters) of sediments, the lack of penetration offered by the chirp data was not an impediment to this study.

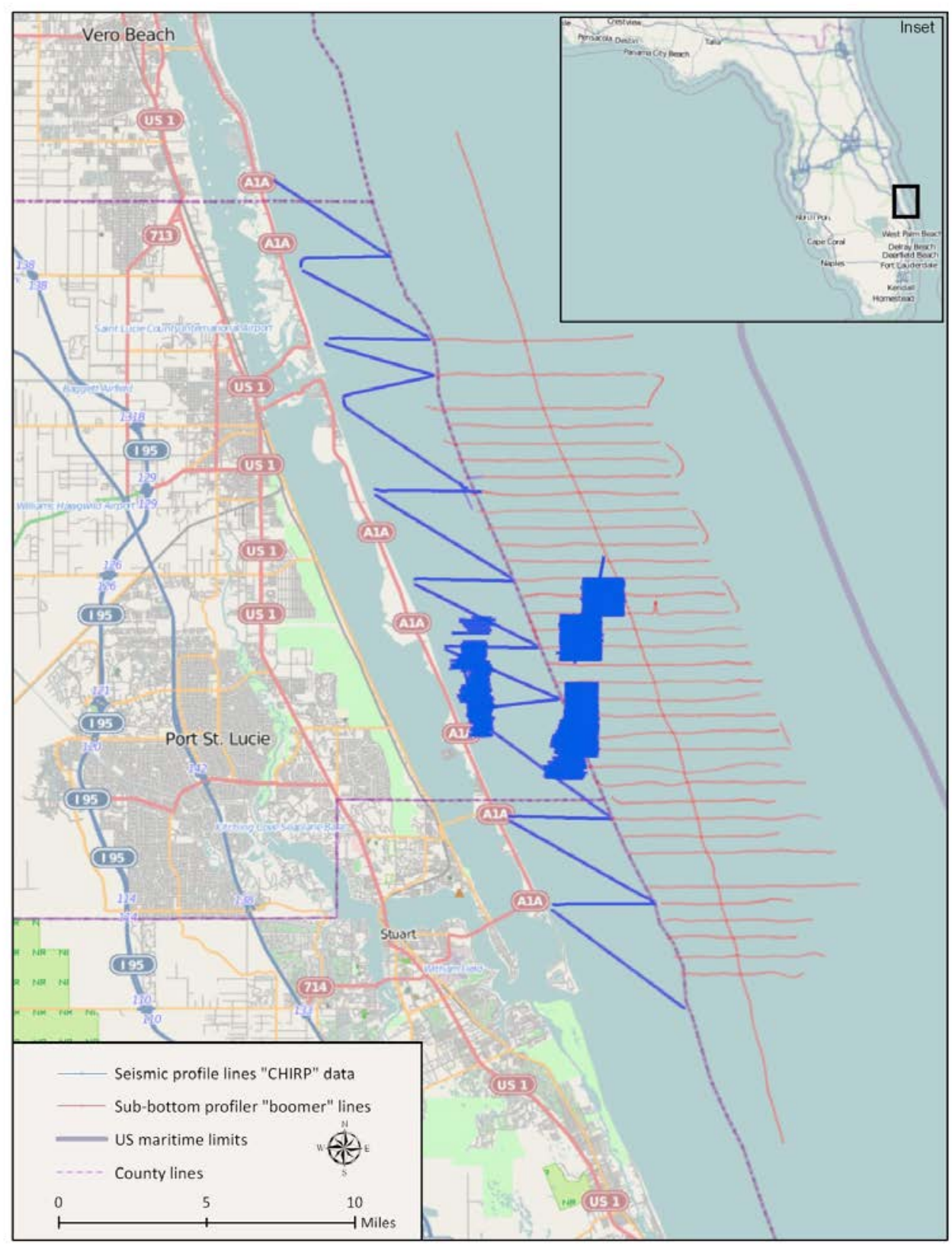

Figure 1. Site map. 


\section{FLORIDA GEOLOGICAL SURVEY}

The chirp data are of relatively high quality while the boomer data vary from fair to poor quality. The chirp data were collected relatively recently and, in spanning a roughly six-year period, are all relatively contemporaneous in time. Data quality is consistent line to line across all three of the chirp surveys. The differences in the resolution of the boomer data (collected in 1998, 1999 and 2000) when compared to the chirp data, make tying the shallow horizon to be mapped from one to the other a questionable endeavor. For these reasons the boomer data were not directly used in the creation of an isopach map displaying the sediment thickness over the "Blue Reflector". Where profiles from the boomer data crossed chirp data profiles, ties were established, when possible, to confirm that the "Blue Reflector" was consistently identified. The map was created using only data obtained from the chirp data. Control for mapping is quite tight over the areas surveyed in the 2006 and 2011 data but substantially less so for the remaining portion of state waters surveyed in the 2007 data.

\section{METHODS}

Seismic reflection profiling is a technique commonly used to delineate structure and bedding planes in sub-seabed sediments and rocks. It is also commonly called sub-bottom or acoustic profiling. Continuous reflections from structure and bedding planes are obtained by generating high frequency sonic impulses and recording the reflections that return from the interfaces between acoustically contrasting sediments. The mapping of reflectors resultant from those interfaces is a straightforward process when those reflectors are continuous and cross-tied by intersecting profiles. Interpolations between parallel or sub-parallel lines that are not cross-tied are based on both the continuity of slope and judgment as to what is geologically reasonable given what occurs elsewhere in the area.

Chirp systems generate a broad band of frequencies. Boomer systems generate a bell shaped curve of frequencies. The acoustic profile generated in either case is created from data recorded in two-way travel time. Two-way travel time is frequently converted to a depth display. When this is done, the resultant profile can be considered comparable to a geologic cross-section.

Chesapeake Technology SonarWiz 5 тм software was utilized in processing and interpreting the data. The software allows the utilization of an interactive seismic workstation approach to data processing and interpretation. This interactive approach facilitates the optimization of post data acquisition processing parameters, the digitization of horizons of interest, and the tying of those horizons from profile to profile to insure that they are consistently identified. The sonic velocity commonly utilized in the processing of subbottom profiler data is $4,921.2 \mathrm{ft} / \mathrm{sec}(1,500 \mathrm{~m} / \mathrm{s})$, i.e. the average velocity of sound in sea water. While this is standard practice in the processing of seismic reflection profiler records, the actual sonic velocity in the near seafloor sediments seen in both the chirp and boomer profiles, due to their higher density relative to sea water, progressively increases with depth. The velocity gradient on Florida's northeast inner continental shelf north of the study area was measured and reported in Meisburger and Field (1975). They divided the sequence into three velocity layers. Their uppermost layer, lying from 0 to $90 \mathrm{ft}(0$ to $27.5 \mathrm{~m})$ below mean sea level (MSL), was estimated to exhibit a sonic velocity approximating that of sea water. Since the digitized horizon used to create the isopach map is entirely contained within the uppermost velocity layer identified in Meisburger and Field (1975), it was determined that the use of $4921.2 \mathrm{ft} / \mathrm{sec}(1,500 \mathrm{~m} / \mathrm{s})$ was appropriate.

Identification of the "Blue Reflector", as the base for delineating the thickness of unconsolidated sediments, was consistent with Meisburger and Duane (1971). In that work (p. 19) they state that: 
The shallowest mapping reflector (referred to as the "blue" reflector) lies just beneath the shelf surface and outcrops at -60 to -70 feet MLW (mean low water). Almost all cores which reached the blue reflector encountered "rocky" material at the reflector level, usually light gray or white calcarenite or sediment containing calcarenite fragments.

They also state (p. 19) that:

While the overlying inner-shelf surface is marked by many low ridges, swales and hills, the blue reflector has an even surface and passes without apparent distortion under shelf irregularities. The seaward dip of about 4 feet per mile ( 1 on 1,300 slope) is parallel to the general dip of the surface of the inner-shelf zone. The blue reflector was selected as a base for the isopach map... because it is the surface of a stratum which persists over a large area, and because the physical characteristics of the stratum and its depth constitute a horizon below which dredging for beach material is presently considered impractical.

The "Blue Reflector" was delineated, in concordance with the blue reflector of Meisburger and Duane (1971), by digitizing the surface of the first coherent, laterally contiguous parallel and relatively flat-lying reflector seen in the seismic sections. In specific seismic profiles which crossed shoals, the reflector was occasionally seen to directly underlie the base of inclined bedding planes. Continuity of the reflector, from profile to profile within the 2006 and 2011 surveys, was established by tying it from east-west trending profiles to north-south trending profiles and/or the profiles of the 2007 survey. When crossing shoals, care was taken to insure that if the reflector was obscured by the water bottom multiple over the top of shoals its continuity was confirmed by tying the reflector back to seismic profiles where the reflector was not obscured. However, as the values at the peak of the shoal were obtained by projecting the "Blue Relector" through the obscuring water bottom multiple, they remain somewhat conjectural.

To create the isopach map of sediments above the "Blue Reflector" layer (Figure 2), both the seabed and "Blue Reflector" surfaces were digitized. Data points were extracted as an XYZ comma separated value file and imported into ESRI's ArcMap ${ }^{\circledR}$ program as an event theme. The points were then exported into a personal geodatabase and projected onto the sea floor. With the points plotted correctly, the Zvalues were used to create a Triangular Irregular Network (TIN) surface. TINs are a form of vector-based digital geographic data and are constructed by triangulating a set of points. The vertices were then connected with a series of edges to form a network of triangles. From there, the TIN surface was converted to a raster or GRID of thickness values and then contoured in one foot ( 0.3 meter) intervals with a base contour of zero. For display purposes every five foot ( 1.5 meter) contour interval was darkened as an index contour.

\section{DISCUSSION}

Acoustic contrasts, which generate reflections, result from the differing physical and acoustic properties inherent in the lithologic differences in layers above and below a reflecting surface. The differences in the physical and acoustic properties of layers of beach restoration quality sand, and sediments that are not of such quality, may not be pronounced enough to generate a distinct reflector. Even if a distinct reflector is generated locally, if gradual lateral facies changes occur that reflector may not be continuous. The analyses presented in this study are preliminary to tying vibracores to specific seismic profiles and thus establishing direct lithologic control for both the base of beach restoration quality sand within the unconsolidated sediments which overly the "Blue Reflector" and the "Blue Reflector" itself. It is intended that further analysis will be done, as time permits, when those data become available. At that point, when vibracores can be tied to specific profiles, the lateral limits of beach restoration quality sand will 


\section{FLORIDA GEOLOGICAL SURVEY}

be delineated and potentially available volumes of beach restoration quality sand within individual shoals can be calculated.

An isopach map of the sediments above the "Blue Reflector" offshore of St. Lucie County is shown in Figure 2. Figure 3 is an enlarged portion of the isopach map shown in Figure 2. Figure 3 encompasses the chirp survey areas of 2006 and 2011 and the portion of the 2007 chirp survey that crosses those areas. Figure 3 depicts sediment thicknesses above the "Blue Reflector", from west to east, in the Pierce and St. Lucie Shoals respectively. The Pierce Shoal lies entirely within state waters while the bulk of the St. Lucie Shoal lies in federal waters. The Pierce Shoal is symmetrical in cross-section. As seen on Figure 3 , its crest is broken into three or possibly four, in echelon, sub-shoals. These sub-shoals are linear with northeast to southwest alignments lying slightly askew to the coastline. The St. Lucie Shoal is

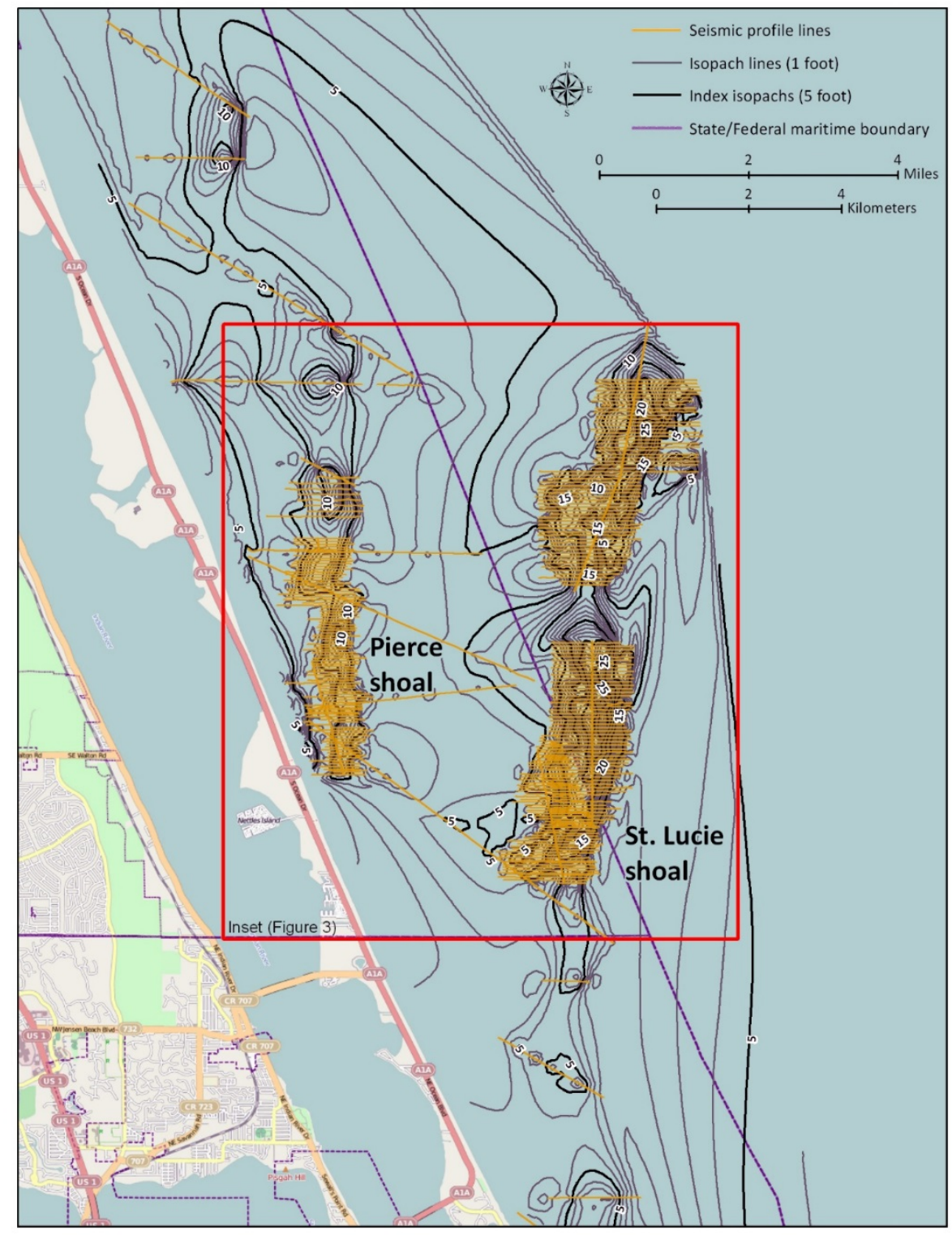

Figure 2. Isopach map of the sediments above the "Blue Reflector". 


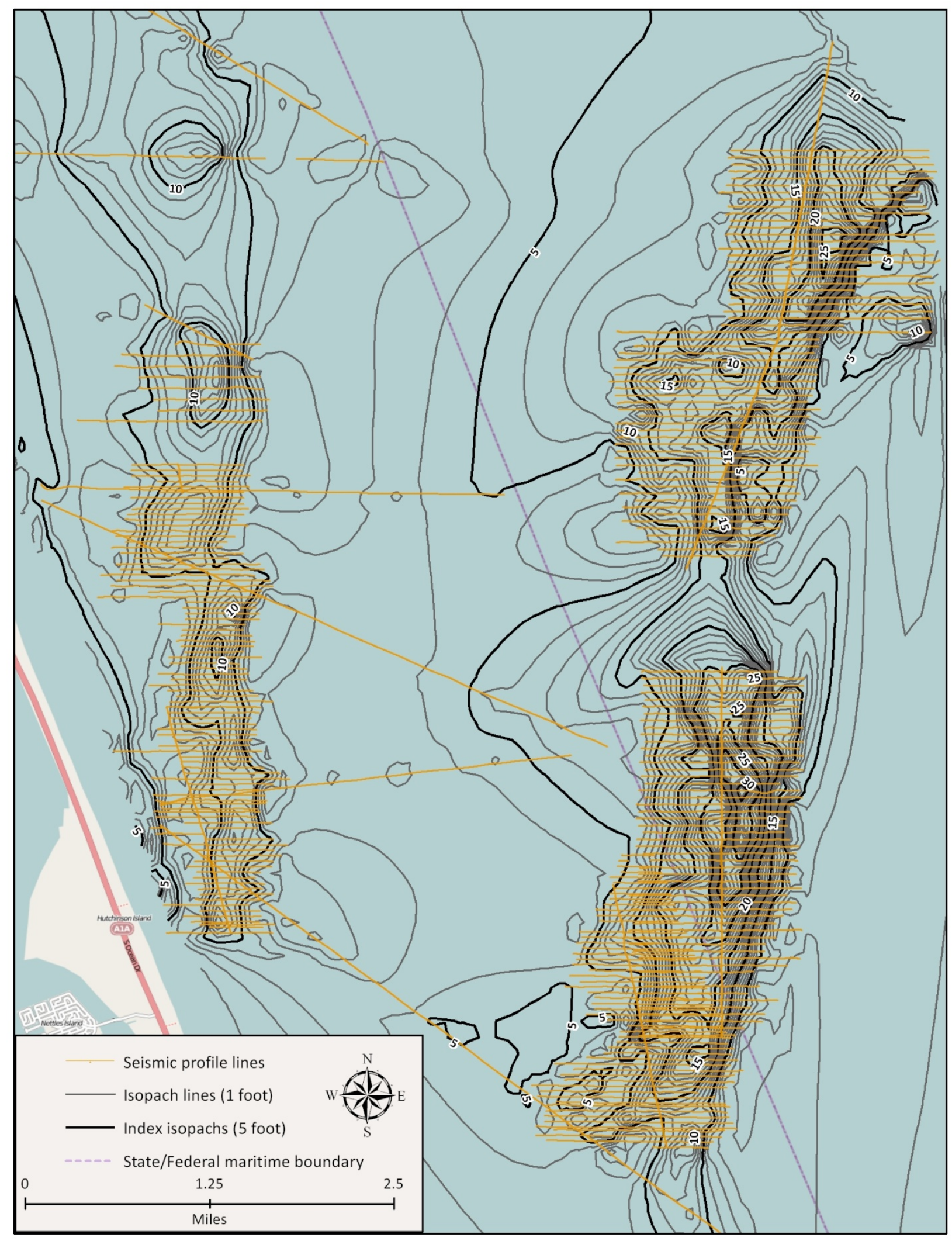

Figure 3. Inset portion of the isopach map. 


\section{FLORIDA GEOLOGICAL SURVEY}

asymmetrical in cross section with its steeper flank facing to the southeast. Its crest is broken into two linear, slightly arcuate, concave to the coast sub-shoals. These sub-shoals, at their northern ends point north and northwest respectively and southwest at their southern ends. The thickest sediment cover over the "Blue Reflector", at over 35 feet (10.7 meters), lies on the crest of the southern sub-shoal of the St. Lucie Shoal. Its northern sub-shoal shows a sediment cover over the "Blue Reflector" of less than 30 feet. In contrast, the Pierce Shoal's thickest sediment cover over the "Blue Reflector" is less than 15 feet (4.6 meters) thick. Sediment cover over the "Blue Reflector", between the Pierce and St. Lucie Shoals and southeast of the southern most of St. Lucie Shoal's two sub-shoals thins to less than five feet (1.5 meters). 


\section{References}

Finkl, C.W., Andrews, J.L., Larenas, M., Benedet, L., and Suthard, B., 2006. South St. Lucie County Hurricane and Storm Damage Reduction Project: 2006 Offshore Geotechnical Investigations to Identify Sand Sources. Boca Raton, Florida: Coastal Planning \& Engineering, Inc., 34p. (Prepared for St. Lucie County, Florida). http://publicfiles.dep.state.fl.us/FGS/FGS Publications/FGS\%20Library\%20Documents/FinklOffs horeGeotechnicalSandSources2006.pdf

Forde, A.S., Dadisman, S.V., Wiese, D.S., and Phelps, D.C., 2013, Archive of digital boomer sub-bottom data collected during USGS cruises 99FGS01 and 99FGS02 offshore southeast and southwest Florida, July and November, 1999: U.S. Geological Survey Data Series 773, 1 DVD, http://pubs.usgs.gov/ds/773

Meisburger, E.P., and Duane D.B., 1971, Geomorphology and sediments of the inner continental shelf, Palm Beach to Cape Kennedy, Florida: U.S. Army Corps of Engineers Technical Memorandum No. 34, 111 p.

http://publicfiles.dep.state.fl.us/FGS/FGS\% 5FPublications/FGS\% 20Library\% 20Document s/CERC-TM-34.pdf

Meisburger, E.P., and Field, M.E., 1975, Geomorphology, shallow structure and sediments of the Florida inner continental shelf, Cape Canaveral to Georgia: U.S. Army Corps of Engineers Technical Memorandum No. 54, $119 \mathrm{p}$.

http://publicfiles. dep.state.fl.us/FGS/FGS\% 5FPublications/FGS\% 20Library\% 20Document s/CERC-TM-54.pdf

Subino, J.A., Dadisman, S.V., Wiese, D.S., Calderon, K., Phelps, D.C., 2009, Archive of digital boomer seismic reflection data collected offshore east-central Florida during USGS cruise 00FGS01, July 14-22, 2000: U.S. Geological Survey Data Series 496, http://pubs.er.usgs.gov/publication/ds496

URS Corporation, Coastal Planning \& Engineering, Inc., 2007, Florida central Atlantic coast reconnaissance offshore sand search (ROSS) - final report: prepared for the Florida Department of Environmental Protection, Bureau of Beaches and Coastal Systems, Tallahassee, Florida, 278 p., http://edocs.dlis.state.fl.us/fldocs/dep/beaches/ross/centralatlanticfinal.pdf 